\title{
Serum interleukin 33 levels and single nucleotide polymorphism rs1929992 in Egyptian patients with chronic asthma
}

The Egyptian Journal of Immunology Volume 28 (4), 2021: 264-271. www.Ejimmunology.org

\author{
Radwa A. Rabea ${ }^{1}$, Randa El-Gamal ${ }^{2}$, Ehab M. \\ Fahmy ${ }^{3}$, Hebatullah K. E. Taha ${ }^{4}$, Asmaa O. Bakr ${ }^{5}$, \\ Maysaa E. Zaki ${ }^{6}$ and Lamiaa M. Elabbasy ${ }^{2}$
}

\author{
${ }^{1}$ Clinical Pathology Department, Faculty of Medicine, Beni \\ Suef University, Beni Suef, Egypt. \\ ${ }^{2}$ Medical Biochemistry Department, Faculty of Medicine, \\ Mansoura University, Mansoura, Egypt. \\ ${ }^{3}$ Medical Microbiology \& Immunology Department, Faculty \\ of Medicine, Aswan University, Aswan, Egypt. \\ ${ }^{4}$ Chest Medicine Department, Faculty of Medicine, Beni \\ Suef University, Beni Suef, Egypt.
}

${ }^{5}$ Clinical Pathology Department, Faculty of Medicine, Asuit University, Asiut, Egypt.

${ }^{6}$ Clinical Pathology Department, Faculty of Medicine, Beni Suef University, Beni Suef, Egypt.

Corresponding author: Radwa A. Rabea, Clinical Pathology Department, Faculty of Medicine, Beni Suef University, Beni Suef, Egypt.

Email: Radwarabea23@yahoo.com.

\begin{abstract}
Bronchial asthma is a common chronic inflammatory disease affecting the airway. Cytokines have a pivotal role in regulation of the immune response, and in development of asthma. Interleukin 33 is a newly discovered member of cytokines, belongs to interleukin 1 family. Previous studies have reported that expression of IL33 is associated with bronchial asthma. This study aimed to evaluate the prevalence of interleukin 33 (IL33) single nucleotide polymorphism (SNP) rs1929992 in asthmatic patients and determine the relation of IL33SNP to IL33 serum level. The Results of RFLP were validated by using sterile distilled water. This study included 100 patients from Egypt, Beni Suef governorate (Upper Egypt) and Mansoura governorate (Delta region), complaining of chronic asthma and 100 control subjects with matched sex and residence. Blood samples from study subjects were used for determination of serum IL33by ELISA and IL33 SNP rs1929992 by PCR-RFLP. There was no significant difference between the proportions of IL33 SNP rs1929992 genotypes in asthma patients and the control group. Allele ' $A$ ' predominates in asthmatics though this did not achieve statistical significance $(P=0.071)$. IL33 level was compared in the three IL33 SNP rs1929992 genotypes; $G / G$, $\mathrm{G} / \mathrm{A}$, and $\mathrm{A} / \mathrm{A}$, and it revealed no significant difference $(P=0.958)$. The association between IL33 with asthma showed that the log-additive model is the best inheritance model which marks allele ' $A$ ' as the risk allele. In contrast, IL33 serum level was significantly higher in severe asthma than the moderate asthma and the mild type $(P<0.0005)$. Spearman's correlation test showed that IL33 level rises as asthma severity increases $(r s=0.880, P<0.0005)$. In conclusion our data revealed no evidence that SNP of IL33 rs1929992 may contribute to the development of asthma in Egyptian population. However, there is a strong positive correlation between IL33 serum level and asthma severity.
\end{abstract}

Keywords: Asthma severity, Alleles, Bronchial asthma, Genotypes, IL33, IL33 SNP rs1929992.

Date received: 07 September 2021; accepted: 29 September 2021 


\section{Introduction}

Bronchial asthma is a common chronic inflammatory disease affecting the airway with hyperresponsiveness, inflammation and reversible airway obstruction. ${ }^{1}$ The affection of the patients with asthma is a multifactorial response involving both environmental and genetic factors that regulate the immune responses. ${ }^{2}$

Cytokines have a crucial role in regulation of the immune response and in development of asthma. There is a newly discovered member of cytokines; interleukin 33 which belongs to interleukin 1 family and its role has been identified to induce $\mathrm{T}$ lymphocytes helper 2 (Th2) cytokines production with amplification of both T lymphocytes helper 1 and T lymphocytes helper 2 responses. ${ }^{3}$ The action of IL33 is mediated via its receptor IL-1 receptor like 1 (IL1RL1), and the IL-1 receptor accessory protein (IL1RACP). ${ }^{4}$ The receptor acts through the activation of signaling protein that leads to the release of allergic and eosinophilic mediators, such as interleukin 5(IL-5) and interleukin 13 (IL13) that leads to eosinophilic inflammation. ${ }^{5}$ The role of interleukin 33 (IL-33) as a strong inducer of Th2 related to the pathogenesis of asthma was reported previously. ${ }^{6}$

Previous studies have reported that expression of IL33 is associated with bronchial asthma, immune regulation, host defense, inflammation with increase in eosinophilic counts and serum IgE level. ${ }^{7}$ Reports of the genome wide association studies about the genetic predisposition to asthma have revealed the association of variations in both IL33 and IL1RL1 within several geographic regions such as Mexican, European, North American and Brazilian populations with asthma. ${ }^{8-10}$ To the best of our knowledge, there are no reports from Egypt about polymorphism of IL33 in association with asthma.

Therefore, the aims of the present study were to evaluate the prevalence of interleukin 33 (IL33) single nucleotide polymorphism (SNP) rs1929992 in patients with asthma and to determine the relation of IL33 single nucleotide polymorphism to serum level of IL33.

\section{Patients and Methods}

This case-control study included 100 patients from, Beni Suef governorate (Upper Egypt) and Mansoura governorate ((Nile Delta region, Egypt) complaining of asthma. In addition, 100 apparently healthy subjects with matched residence, and sex acted as a control group. Patients were recruited from Beni Suef University hospital, and Mansoura University Hospital. The research protocol was reviewed and approved by the Institutional Review Board Committee at the Faculty of Medicine, Mansoura University (R/19.06.526; 7/2019). A written consent was signed by each of the participants in the study.

The diagnosis of patients with asthma was confirmed by clinical history and medical examination. Asthma is defined as reversible airway obstruction with an increase of forced expiratory volume (FEV) in 1 second by $12 \%$ after 15 minutes of salbutamol inhalation (400 $\mu \mathrm{g} / \mathrm{spacer}$ ). According to the National Heart, Lung, and Blood Institute 2007, the severity of asthma was classified into 4 grades; intermittent ( $\leq$ twice/week, FEV1 > 80\%; grade 1 ), mild persistent ( $\geq$ twice/week, FEV1 $>80 \%$; grade 2), moderate persistent (FEV1 60-80\%; grade 3 ), and severe persistent (FEV1 < 60\%; grade 4). ${ }^{11}$

Patients were excluded if below 18 years or complaining of other chronic diseases.

Ten milliliter blood samples were withdrawn from all subjects and divided to three aliquots. The first aliquot was for full blood counts by Sysmex clinical hematology analyzer (USA). The second aliquot was for serum separation and determination of IL3 by the Enzyme Linked Immunosorbent Assay (ELISA) using a commercial kit (ELISA- PicoKine-3942 B Valley Ave, Pleasanton, CA 94566). The third aliquot was collected on EDTA for DNA extraction, from whole blood samples, for molecular study of IL33 SNP rs1929992 by polymerase chain reaction-restriction fragment length polymorphism (PCR-RFLP).

\section{Measurement of IL33 by ELISA}

Human IL33 pre-coated ELISA plates (ELISAPicoKine-3942 B Valley Ave, Pleasanton, CA 
94566) was used in this study. The detection antibody was a biotinylated antibody specific for IL33. The capture antibody was a monoclonal antibody from mouse, and the detection antibody, a polyclonal antibody from goat. To measure human IL33, standards and samples were added to assigned wells, then the biotinylated detection antibody was added. The wells were washed with phosphate buffered saline (PBS), and Avidin-Biotin-Peroxidase Complex (ABC-HRP) was added. The unbounded ABC-HRP was washed away with PBS and 3,3',5,5'-Tetramethylbenzidine (TMB) was added. TMB is the substrate of HRP which catalyzed the production of a blue color product, changed into yellow after adding an acidic stop solution. The density of the yellow product is linearly proportional to human IL33 in the sample. All reagents were provided in the ELISA kit. The density of the yellow product was read in all wells using an ELISA plate reader (Sunrise Tecan Magellan ELISA reader, Tecan Austria $\mathrm{GmbH}$ ). The readings of samples were compared against a standard curve to determine the concentration of human IL33 in the samples. ${ }^{12}$ The concentration was defined as $\mathrm{pg} / \mathrm{ml}$. Results of ELISA were validated using standards provided in the kit.

\section{Molecular Study of IL33- SNP rs1929992}

- Extraction of DNA: The blood samples from all participants were subjected to DNA extraction by Qiagen extraction kit from whole blood (QIAamp DNA Blood Mini Kit, Qiagen, Germany), according to the manufacturer's instructions. The extracted DNA was kept frozen at $-20^{\circ} \mathrm{C}$ till used in the amplification process.

- The Polymerase Chain Reaction-Restriction Fragment Length Polymorphism (PCR-RFLP): The extracted DNA was used for the amplification of rs1929992 IL33 (Qiagen-USA). At first, the amplification method was performed for IL-33 gene rs1929992 by the use of $1 \mu \mathrm{l}$ of the extracted DNA, which was added to 12.5 microns of ready to use amplification mixture supplied by Qiagen. The used primers were (F:5'-GAAGTCATCATCAACTTGGAACC- 3 ), R:5'-GGATTGGAATCCCATGGTC- ${ }^{-3}$ ). The PCR program was as follows: a first step at $95{ }^{\circ} \mathrm{C}$ for 10 minutes, followed by 35 cycles including denaturation phase at $95{ }^{\circ} \mathrm{C}$ for 30 seconds, annealing at $61{ }^{\circ} \mathrm{C}$ for 30 seconds and a last elongation phase at $72{ }^{\circ} \mathrm{C}$ for 30 seconds. The PCR product was $300 \mathrm{bp}$. The amplified PCR product of SNP rs1929992 then was digested using restriction enzyme Sspl (New England Biolabs, Beverly, MA, USA) according to the manufacturer's instructions. Agarose gel electrophoresis $2.5 \%$ was used to visualize the PCR products. The GG genotype yielded a 217 bp fragment, the heterozygotic AG yielded three different fragments with 217, 134 and 83 bp; and AA yielded fragments with 134 and 83 bp. ${ }^{13}$ Results of RFLP were validated by using sterile distilled water.

\section{Statistical analysis}

Data were entered and analyzed using IBM SPSS Statistics for Windows, Version 25.0. (IBM Corp. Released 2017, Armonk, NY: IBM Corp). Qualitative data were expressed as frequency and percentage and compared by the ChiSquare test. Quantitative data were initially tested for normality using Shapiro-Wilk's test with data being normally distributed if $P>0.050$. Quantitative data were expressed as meantstandard deviation (SD) if normally distributed, or as median and interquartile range (IQR) if not. Quantitative data between two groups were compared by IndependentSamples t-test or its non-parametric alternative Mann-Whitney $U$ test. Quantitative data between more than two groups were compared by One-way ANOVA test or its non-parametric alternative Kruskal-Wallis $\mathrm{H}$ test. Pairwise comparisons were performed if the result was significant. Spearman's correlation was used as a measure of the strength and direction of the association/relationship between two continuous or ordinal variables. Log additive model was used, as it is a nonparametric regression method being more flexible than a standard linear model. For any of the used tests, results were considered as statistically significant if $p$ value $\leq 0.050$. Appropriate charts were used to graphically present the results whenever needed. SNP analysis was performed online through SNP Stats software (https://www. snpstats.net/start.htm). 


\section{Results}

Clinical, demographic and laboratory parameters in the two study groups

The study was carried out on 100 patients with asthma from Upper Egypt Bani Suef governorate and lower Egypt-Delta region, Mansoura and 100 normal subjects not suffering from asthma as a control group. The median (interquartile range) of patients was 45.5 (39.3-54.8) years and 54.5 (45-59) years for the control subjects. There was a statistically significant difference between the age of both groups $(P<0.0005)$. Patients and control groups were mainly female $(65 \%$ and $60 \%$, respectively). The smoking was a frequent habit in $33 \%$ of patients, and in $30 \%$ of controls. The frequency of asthma was mainly in individuals from rural areas. There was a statistically significant difference in total leucocytic count, hemoglobin level, platelet count and II33 serum level between both groups $(P<0.0005, P=0.040$, $P<0.0005$, and $P<0.0005$, respectively) as shown in Table 1.

Table 1. Clinical, demographic and laboratory parameters in the two study groups:

\begin{tabular}{|c|c|c|c|}
\hline Variable & $\begin{array}{l}\text { Control } \\
(n=100)\end{array}$ & $\begin{array}{l}\text { Asthma } \\
(n=100)\end{array}$ & $P$ value \\
\hline Age (years) & $54.5(45-59)$ & $45.5(39.3-54.8)$ & $<0.0005$ \\
\hline \multicolumn{4}{|l|}{ Sex frequency: } \\
\hline Male & 40 & 35 & *NS \\
\hline Female & 60 & 65 & \\
\hline Current smoking frequency, yes & 23 & 33 & *NS \\
\hline \multicolumn{4}{|l|}{ Residency frequency: } \\
\hline Rural & 62 & 70 & $*$ NS \\
\hline Urban & 38 & 30 & \\
\hline Total leucocyte count $\left(* 10^{3} / \mu\right.$ l blood $)$ & $5.3(4.6-6.8)$ & $6.5(5.0-8.4)$ & $<0.0005$ \\
\hline Polymorphs \% & $48(39-57.3)$ & $50(42-58)$ & NS \\
\hline Lymphocytes \% & $43(34-48)$ & $39(30.5-48)$ & NS \\
\hline Hemoglobin (g/dl) & $12.5(11.2-13.3)$ & $12.6(11.4-14.2)$ & 0.040 \\
\hline Platelet count $\left(* 10^{3} / \mu\right.$ l blood $)$ & $201.5(179.8-255.8)$ & $178(131.3-216.3)$ & $<0.0005$ \\
\hline IL33 (pg/ml) & $17(14-19.8)$ & $45(39.8-57)$ & $<0.0005$ \\
\hline
\end{tabular}

Asthmatic patients were classified according to the frequency of asthma and FEV into three groups: intermittent/mild persistent (24\%), moderate persistent (37\%), and severe persistent (39\%) as shown in Figure 1.

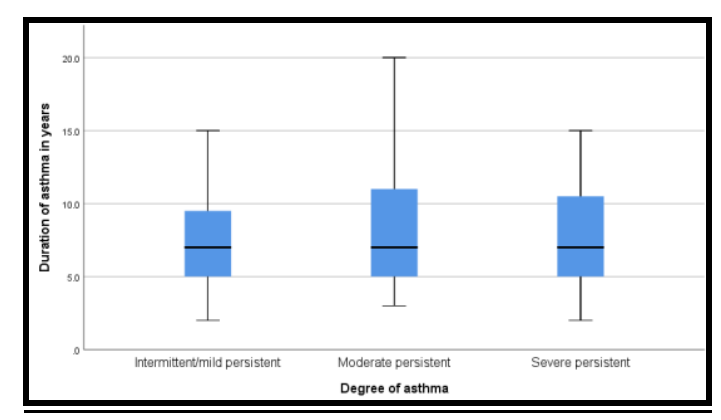

Figure 1. Duration and severity of asthma. This figure shows different types of asthma severity with the median (interquartile range) of asthma duration in each type.

\section{IL33 genotype and allele frequencies}

There was no significant difference in the proportions of IL33 SNP rs1929992 genotypes in asthmatic patients and the control group (Table 2). Allele ' $A$ ' predominates in asthmatics though this did not achieve a statistical significance $(P=0.071)$ (Table 3 and Figure 2). There was a hardy-Weinberg equilibrium for all subjects; asthmatics and controls (Table 4).

Table 2. Frequencies of IL33 genotypes.

\begin{tabular}{|c|c|c|c|}
\hline \multirow[b]{2}{*}{ Genotype } & \multicolumn{2}{|c|}{ Group } & \multirow[b]{2}{*}{${ }^{*} P$ value } \\
\hline & $\begin{array}{l}\text { Control } \\
(n=100)\end{array}$ & $\begin{array}{l}\text { Asthma } \\
(n=100)\end{array}$ & \\
\hline $\mathrm{G} / \mathrm{G}$ & 25 & 17 & \multirow{3}{*}{ NS } \\
\hline $\mathrm{G} / \mathrm{A}$ & 50 & 48 & \\
\hline$A / A$ & 25 & 35 & \\
\hline
\end{tabular}

$* P$ value by Chi-Square Test. $P>0.05$ is not significant (NS). 
Table 3. Frequencies IL33 alleles.

\begin{tabular}{lccc}
\multicolumn{1}{c}{ Allele } & Asthma & Control & ${ }^{*} P$ value \\
\cline { 1 - 3 } $\mathrm{A}$ & $118(59 \%)$ & $100(50 \%)$ & \multirow{2}{*}{ NS } \\
\cline { 1 - 3 } $\mathrm{G}$ & $82(41 \%)$ & $100(50 \%)$ & \\
\cline { 1 - 2 }$* P>0.05$ & is not significant (NS) & &
\end{tabular}

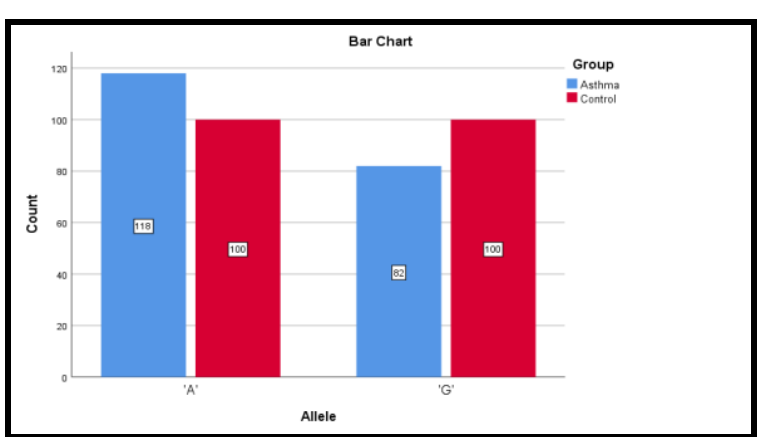

Figure 2. IL33 allele frequencies. This figure shows that allele ' $A$ ' predominates in asthmatics than the control group.

Table 4. IL33 exact test for Hardy-Weinberg equilibrium.

\begin{tabular}{ll}
\hline \multicolumn{1}{c}{ Subjects } & ${ }^{*} \boldsymbol{P}$ value \\
\hline All & NS \\
\hline Case (asthma) & NS \\
\hline Control & NS \\
\hline$P>0.05$ is not significant (NS) &
\end{tabular}

$P>0.05$ is not significant (NS).

\section{IL33 level in different genotypes}

Kruskal-Wallis test was run to compare the IL33 level in the three IL33 SNP rs1929992 genotypes; G/G, G/A, and A/A. The median and interquartile range (IQR) levels were 51 (39-58) $\mathrm{pg} / \mathrm{ml}, 46$ (40-56.8) pg/ml, and 44 (39-57) $\mathrm{pg} / \mathrm{ml}$, respectively. It revealed no significant difference $(P=0.958)$ (Figure 3$)$.

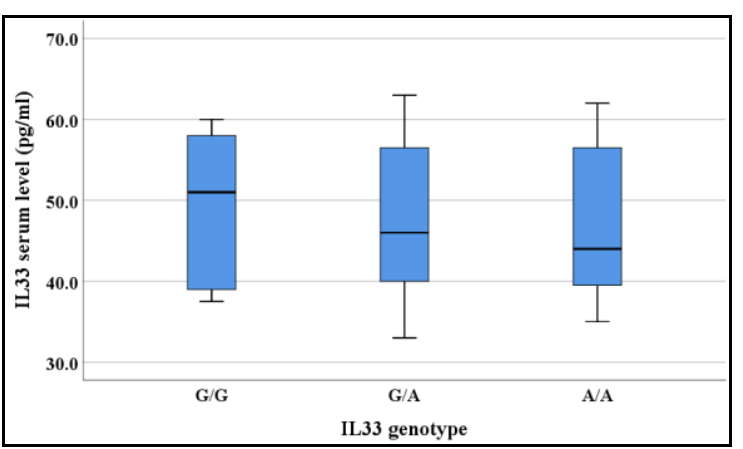

Figure 3. IL33 level in different genotypes. Kruskal-Wallis test was run to compare the IL33 serum level in the three IL33 genotypes; G/G, G/A, and A/A. Median and interquartile range (IQR) levels were 51 (3958), 46 (40-56.8), and 44 (39-57), respectively. It revealed no statistically significant difference $(P=0.958)$.

\section{IL33 SNP rs1929992association with asthma}

The association between IL33 with asthma was adjusted by age and gender and showed that the log-additive model is the best inheritance model which marks allele ' $A$ ' as the risk allele. Choosing log-additive model as the best inheritance model as it has the lowest $p$ value, AIC and BIC values (Table 5). When IL33 was cross classified with gender, this showed that male with genotype G/G has 5.56 times higher odds to exhibit control status rather than asthma as compared to the reference category (female with A/A genotype) (Table 6).

Table 5. IL33 association with asthma (adjusted by age and gender).

\begin{tabular}{|c|c|c|c|c|c|c|}
\hline Model & Asthma $(n=100)$ & Control $(n=100)$ & OR $(95 \% \mathrm{Cl})$ & ${ }^{*} P$ value & AIC & $\mathrm{BIC}$ \\
\hline \multicolumn{7}{|l|}{ Codominant: } \\
\hline $\mathrm{A} / \mathrm{A}$ & 35 & 25 & $\mathrm{R}$ & \multirow{3}{*}{ NS } & \multirow{3}{*}{260} & \multirow{3}{*}{276.5} \\
\hline$G / A$ & 48 & 50 & $1.65(0.82-3.29)$ & & & \\
\hline $\mathrm{G} / \mathrm{G}$ & 17 & 25 & $2.36(1.00-5.61)$ & & & \\
\hline \multicolumn{7}{|l|}{ Dominant: } \\
\hline $\mathrm{A} / \mathrm{A}$ & 35 & 25 & $\mathrm{R}$ & \multirow[t]{2}{*}{ NS } & \multirow[t]{2}{*}{258.8} & \multirow[t]{2}{*}{272} \\
\hline$G / A-G / G$ & 65 & 75 & $1.83(0.95-3.52)$ & & & \\
\hline \multicolumn{7}{|l|}{ Recessive: } \\
\hline$A / A-G / A$ & 83 & 75 & $\mathrm{R}$ & \multirow[t]{2}{*}{ NS } & \multirow[t]{2}{*}{260} & \multirow[t]{2}{*}{273.2} \\
\hline $\mathrm{G} / \mathrm{G}$ & 17 & 25 & $1.74(0.82-3.65)$ & & & \\
\hline \multicolumn{7}{|c|}{ Over dominant: } \\
\hline$A / A-G / G$ & 52 & 50 & $\mathrm{R}$ & \multirow[t]{2}{*}{ NS } & \multirow[t]{2}{*}{261.9} & \multirow[t]{2}{*}{275.1} \\
\hline $\mathrm{G} / \mathrm{A}$ & 48 & 50 & $1.16(0.64-2.11)$ & & & \\
\hline Log-additive & -- & -- & $1.55(1.01-2.38)$ & 0.042 & 258 & 271.2 \\
\hline
\end{tabular}


Table 6. IL33 and Gender cross-classification interaction table (adjusted by Age).

\begin{tabular}{lcccccc}
\hline Genotype & \multicolumn{3}{c}{ Female $(n=125)$} & \multicolumn{3}{c}{ Male $(n=75)$} \\
\cline { 2 - 8 } & $\begin{array}{c}\text { Asthma } \\
(n=65)\end{array}$ & $\begin{array}{c}\text { Control } \\
(n=60)\end{array}$ & OR (95\%) Cl & $\begin{array}{c}\text { Asthma } \\
(n=35)\end{array}$ & $\begin{array}{c}\text { Control } \\
(n=40)\end{array}$ & OR (95\%) Cl \\
\hline A/A & 22 & 13 & $R$ & 13 & 12 & $1.41(0.48-4.19)$ \\
\hline G/A & 31 & 35 & $2.00(0.82-4.88)$ & 17 & 15 & $1.62(0.57-4.61)$ \\
\hline G/G & 12 & 12 & $1.73(0.56-5.35)$ & 5 & 13 & $5.56(1.44-21.44)$ \\
\hline
\end{tabular}

OR (95\% Cl): Odds ratio (95\% confidence interval), R: Reference category. $P>0.05$ is not significant (NS).

\section{IL33 and asthma severity}

IL33 level was significantly higher in severe asthma than the moderate asthma and more than the mild type $(P<0.0005)$ (Figure 4). Spearman's correlation test was run to test for the correlation between IL33 level and asthma severity. This test showed that IL33 level rises as asthma severity increases ( $r \mathrm{~s}=0.880, P<0.0005)$.

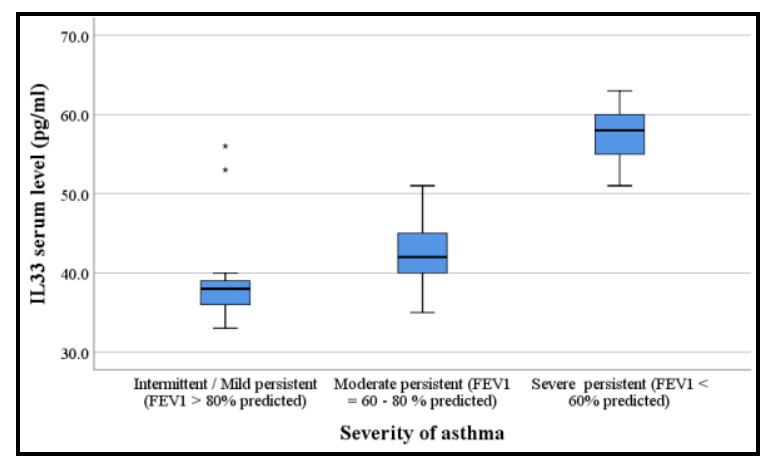

Figure 4. IL33 serum level and asthma severity. IL33 level is statistically significantly higher in severe asthma than in moderate and mild persistent asthma.

\section{Discussion}

The current study attempted to determine the relationship between SNP rs1929992 and the risk of bronchial asthma. To the best of our knowledge, this is the first report to identify such relation in Egypt. This study showed that there was a no difference in the proportions of IL33 SNP rs1929992 genotypes in asthma and control groups. In addition, the present study reported significantly higher serum IL-33 levels in adult asthmatic patients in comparison to the control group. Moreover, we noted a linear rise in serum IL-33 levels with increased asthma severity. These findings are in line with one meta-analysis that included 15 studies recruiting 633 asthmatic patients and 379 controls. Pooling of the studied data revealed that asthmatic patients had significantly higher serum IL-33 levels in comparison to controls. ${ }^{14}$ Furthermore, in the asthmatic group, those with more severe disease had significantly higher IL33 levels. ${ }^{14}$

Likewise, two recent studies of Momen et al., 2017 and Gasiuniene et al., 2019, reported corresponding data. ${ }^{18-19}$ Nonetheless, the latter study of Gasiuniene et al., 2019, failed to find a significant relation between asthma severity and IL-33 levels. ${ }^{15}$ In support of our conclusions, the study of Glück et al., 2016, reported that even in the exhaled breath condensate of chronic asthma patients, IL-33 levels were significantly higher when compared with their levels in study controls. ${ }^{16}$

Similar conclusions were documented by another meta-analysis restricted to studies conducted on children. ${ }^{17}$ The principle mechanism of IL-33 is mediated through its binding to IL-1 receptor-like 1 with the formation of a receptor complex with IL-1 receptor-associated protein. This complex leads to the release of allergic and eosinophilic mediators, like IL-5 and IL-13 and results in eosinophilic inflammation. ${ }^{18-19}$

The distinguished finding of the present study was the significant correlation between IL33 serum level and the degree of asthma. A previous study reported a significant correlation with IL33 and the disease activity in children with asthma. Therefore, serum level of IL33 may be considered a reliable biomarker of the severity of the asthma. ${ }^{20}$

In conclusion, the present study suggested that SNP rs1929992 of IL-33 gene is not associated with risk of bronchial asthma. However, higher serum IL-33 levels are strongly associated with asthma severity in Egyptian adults. 


\section{Author Contributions}

RAR, RE and LME; data analysis, participation in designing the study, read and approve the final manuscript. EMF, HKET and AOB; formulation of the research question and statement of hypothesis, wrote the first draft of the manuscript, read and approve the final manuscript. EZ; supervising the research, designed the study and wrote the protocol, manage the practical part.

\section{Declaration of Conflicting Interests}

The author(s) declared no potential conflicts of interest with respect to the research, authorship, and/or publication of this article.

\section{Funding}

The author(s) denies receipt of any financial support for the research, authorship, and/or publication of this article.

\section{Ethical approval}

The research protocol was reviewed and approved by the Institutional Review Board Committee at the Faculty of Medicine, Mansoura University (R/19.06.526; 7/2019).

\section{Informed consent}

A written consent was signed by each of the participants in the study.

\section{References}

1. McLeish S and Turner SW. (2007). Geneenvironment interactions in asthma. Arch Dis Child; 92:1032-35.

2. Heinzmann A, Bauer E, Ganter K, et al. (2005). Polymorphisms of the TGF-beta1 gene are not associated with bronchial asthma in Caucasian children. Pediatr Allergy Immunol; 16:310-14.

3. Liew FY, Pitman NI, Mcinnes IB. (2010). Diseaseassociated functions of IL-33: the new kid in the IL-1 family. Nat Rev Immunol; 10 (2):103-10.

4. Chackerian AA, Oldham ER, Murphy EE, et al. (2007). IL-1 receptor accessory protein and ST2 comprise the IL-33 receptor complex. J Immunol; 179(4):2551-5.

5. Moussion C, Ortega N, Girard JP. (2008). The IL-1like cytokine IL-33 is constitutively expressed in the nucleus of endothelial cells and epithelial cells in vivo: a novel 'alarmin'? Plos One; 3(10):e3331.

6. likura M, Suto H, Kajiwara N, et al. (2007). IL-33 can promote survival, adhesion and cytokine production in human mast cells. Lab Invest; 87:97178.

7. Kearley J, Buckland KF, Mathie SA, et al. (2009). Resolution of allergic inflammation and airway hyper-reactivity is dependent upon disruption of the T1/ST2-IL-33 pathway. Am J Respir Crit Care Med; 179(9):772-81. doi: 10.1164/rccm.200805-6660C.

8. Moffatt MF, Gut IG emenais F, et al. (2010). A large-scale, consortium-based genome-wide association study of asthma. $N$ Engl Med; 363(13):1211-21.

9. Torgerson DG, Ampleford EJ, Chiu GY, et al. (2011). Meta-analysis of genome-wide association studies of asthma in ethnically diverse North American populations. Nat Genet; 43(9):887-92.

10. Wu H, Romieu I, Shi M, et al. (2010). Evaluation of candidate genes in a genome-wide association study of childhood asthma in Mexicans. J Allergy Clin Immunol; 125(2):658-61.

11. National Heart, Lung, and Blood Institute, National Asthma Education and Prevention Program. Bethesda: National Heart, Lung, and Blood Institute; 2007. Expert Panel Report 3: Guidelines for the Diagnosis and Management of Asthma. [Last accessed on Jan 23, 2017]. Available at: http://www.nhlbi.nih.gov/guidelines/asthma/.

12. Engvall E, Perlmann P. (1971). Enzyme linked immunosorbent assay (ELISA). Quantitative assay of immunoglobulin G. Immunochemistry; 8, 871-74.

13. Jafarzadeh A, Minaee K, Farsinejad AR, et al. (2015). Evaluation of the circulating levels of IL-12 and IL-33 in patients with breast cancer: influences of the tumor stages and cytokine genepolymorphisms. Iran J Basic Med Sci; 18(12):1189-98.

14. Li R, Yang G, Yang Ret al. (2015). Interleukin-33 and receptor ST2 as indicators in patients with asthma: a meta-analysis. Int J Clin Exp Med; 8(9): 14935-43.

15. Gasiuniene E, Janulaityte I, Zemeckiene Z, et al. (2019). Elevated levels of interleukin-33 are associated with allergic and eosinophilic asthma. Scand J Immunol, 89(5):e12724.

16. Glück J, Rymarczyk B, Kasprzak M, et al. (2016). Increased Levels of Interleukin-33 and Thymic Stromal Lymphopoietin in Exhaled Breath Condensate in Chronic Bronchial Asthma. Int Arch Allergy Immunol; 169(1):51-6.

17. Wang Y, Wang L, Hua S. (2017). Interleukin-33 in children with asthma: A systematic review and metaanalysis. Allergol Immunopathol (Madr); 45(4):38792.

18. Savenije OEM, Kerkhof $M$, Reijmerink NE, et al. (2011). Interleukin-1 receptor-like 1 polymorphisms 
are associated with serum IL1RL1-a, eosinophils, and asthma in childhood. J Allergy Clin Immunol; 127(3):750-56.

19. Hamzaoui A, Berraies A, Kaabachi W, et al. (2013). Induced sputum levels of IL-33 and soluble
ST2 in young asthmatic children. J Asthma; 50(8):803-9.

20. Kim YH, Yang TY, Park CS, et al. (2012). Anti-IL-33 antibody has a therapeutic effect in a murine model of allergic rhinitis. Allergy; 67: 183-90. 